\title{
Dizygotic Twinning, Birth Order, Female Psychology, and Coital Rates
}

\author{
William H. James \\ MRC Mammalian Development Unit, Wolfson House, 4 Stephenson Way, \\ London NW1 2HE
}

It is well established that the dizygotic (DZ) twinning rate increases with maternal age until about age 38 and thereafter declines, and that within each maternal age category, it increases (apparently indefinitely) with parity [5]. Interpretation of this increase with parity is not immediately clear. One may formulate two hypotheses, one or both of which may be true.

Hypothesis 1: Twin-prone women are more fertile than other women and therefore they form a progressively increasing proportion of the mothers at each birth rank and/or

Hypothesis 2: Each birth somehow adds an increment to a woman's probability of bearing a $\mathrm{DZ}$ twin pair at her next pregnancy.

Allen [1] tested the latter hypothesis in the following way. For a group of sibships all of the same size, and all of which contained a pair of DZ twins, he considered only those pregnancies occurring in a given limited age range, e.g., 25-29. The test consisted in observing whether the twin maternities were then related to birth order within this age range. He found that they were. Accordingly, he drew the inference that the second hypothesis was true.

This led him [2] to question the evidence which had seemed to support hypothesis 1. Among the sorts of evidence he considered were the prompt postmarital conceptions [4,9] and prompt postwar conceptions $[3,8]$ of DZ twins. He found that within the reproductive histories of women bearing $\mathrm{DZ}$ twins, the conception delays leading to first-born $\mathrm{DZ}$ twin pairs were less than those leading to first-born singletons. Though he admits that the difference was not significant, he writes: "It probably means that prompt conception is not a constant characteristic of parents of twins; their chance of early conception need not be any greater than that of other couples." It seems to me that (even if the difference were significant) the argument is misleading. The contrast that would be interesting is between the conception delays preceding first-born singletons in DZ twin sibships and the first conception delays in other sibships. If there were no difference between them, then Allen's suggestion would be vindicated.

In support of his case, Allen writes [2]: "It seems as if the marriage event itself promotes twinning; and so does return of husbands from war, or an illicit love affair." 
He suggests that one precipitant of double ovulation is psychological. It seems to me that coital rates rather than female psychology offer a better explanation of the data.

For the present purpose, one may well suppose that the event of marriage, and the return of husbands, and illicit love affairs all have similar psychological effects on women. And-except in one important respect-these events may all be presumed to have promotional effects on coital rates, too. The exception is that the coital rates of young (under 20) unmarried (coitally active) women are substantially less than those of young married women [6].

Now in England and Wales, the DZ twinning rate of unmarried women aged less than 20 is lower than the comparable rate for married women [6]. This was so for every fiveyear period from 1938 to 1978 . I argued that this difference was not due to reporting deficiencies nor to maternal age differences, and inferred that coital rates play an important role in the production of DZ twins. Certainly it seems fair to conclude that their role is larger than that of female psychology.

So I suggest that hypothesis 1 above (as well as hypothesis 2 ) is true. Women who bear DZ twins are more fertile. And this is at least partially because they have higher coital rates.

The question arises: Does female psychology play any role in double ovulation? Parisi and Caperna [8] noted that the recent secular decline in DZ twinning rates in Italy showed some parallels with increasing industrialization there. They raised the possibility of a causal link via emotional stress. However, a similar decline in $\mathrm{DZ}$ twinning rates has occurred in the rest of Western Europe and in Canada but scarcely at all in the United States [7]. Yet if stress is increasing in the rest of the western world, it seems odd not to suppose that it is increasing in the United States.

There seems no very convincing evidence that female psychological involvement either enhances or diminishes the probability of double ovulation (though one may wonder whether high coital rates raise this probability).

\section{REFERENCES}

1. Allen G (1978): The parity effect and fertility in mothers of twins. Prog Clin Biol Res 24B:89-97.

2. Allen G (1981): The twinning and fertility paradox. Prog Clin Biol Res 69A:1-13.

3. Allen G, Schachter J (1971): Ease of conception in mothers of twins. Soc Biol 18:18-27.

4. Bulmer MG (1959): The effect of parental age, parity and duration of marriage on the twinning rate. Ann Hum Genet 23:454-458.

5. Heuser RL (1967): "Multiple Births, United States, 1964." Washington: US Government Printing Office (PHS Publication No. 1000, Series 21 No 14).

6. James WH (1981): Dizygotic twinning, marital stage and status and coital rates. Ann Hum Biol 8:371-378.

7. James WH (in press): Second survey of secular trends in twinning rates. $J$ Biosoc Sci.

8. Parisi P, Caperna G (1981): The changing incidence of twinning: One century of Italian statistics. Prog Clin Biol Res 69A:35-48.

9. Pollard GN (1969): Multiple births in Australia 1944-63. J Biosoc Sci 1:389-404. 